\title{
Relapses and disease-modifying drug treatment in pregnancy and live birth in US women with MS
}

Maria K. Houtchens, MD, MMSc, Natalie C. Edwards, MSc, and Amy L. Phillips, PhD

Neurolog ${ }^{\circledR}$ 2018;91:e1570-e1578. doi:10.1212/WNL.0000000000006382

\author{
Correspondence \\ Dr. Houtchens \\ mhoutchens@ \\ bwh.harvard.edu
}

\section{RELATED ARTICLE}

\section{Editorial}

Pregnancy in multiple sclerosis: Data from an administrative claims database

Page 771

\section{Results}

A total of 2,158 patients were eligible. The odds of relapse declined during pregnancy (odds ratio [OR] 0.623, 95\% confidence interval [CI] 0.521-0.744; $p<0.0001$ ), increased during puerperium (OR 1.710, 95\% CI 1.358-2.152; $p<0.0001$ ), and ended at a higher level during the last 3 postpartum quarters (OR 1.216, 95\% CI 1.052-1.406; $p=0.0081$ ). The proportion of women with DMD treatment was rather low overall: approximately $20 \%$ prepregnancy, bottoming to $1.9 \%$ during the second trimester, and peaking at $25.5 \% 9$ to 12 months postpartum. DMD treatment declined significantly during pregnancy (OR 0.171, 95\% CI 0.144-0.203; $p<$ 0.0001 ), remained lower during puerperium (OR 0.361, 95\% CI 0.312-0.418; $p<0.0001$ ), and ended at a higher level during the last 3 postpartum quarters (OR 1.259, 95\% CI 1.156-1.371; $p<0.0001)$.

\section{Conclusions}

The rate of MS relapse decreased during pregnancy, increased 6 months postpartum, and decreased 6 to 12 months postpartum. DMD treatment was uncommon in the year before pregnancy, further decreased immediately prepregnancy and during pregnancy, and increased postpartum. 


\section{Glossary}

CI = confidence interval; DMD = disease-modifying drug; ER = emergency room; ICD-9-CM = International Classification of Diseases, Ninth Revision, Clinical Modification; MS = multiple sclerosis; OR = odds ratio.

To identify opportunities to improve care of patients with multiple sclerosis (MS) and pregnancy, it is important to understand patients' burden of disease and real-world treatment approaches. There is a paucity of published research pertaining to disease burden and treatment patterns for women with MS and pregnancy. Six prospective ${ }^{1-6}$ and 4 retrospective studies $^{7-11}$ ranging in size from 29 to 254 patients have evaluated relapse rates before, during, and after pregnancy. One study was international, ${ }^{4} 6$ were European, ${ }^{1-3,5,6,10} 2$ were South American, ${ }^{8,9}$ one Russian, $^{11}$ and one Lebanese. ${ }^{7}$ Overall, findings showed that relapse rates decreased during pregnancy, increased during puerperium, and then returned to prepregnancy levels. ${ }^{1-11}$ Details regarding the nature of intrapartum or postpartum relapses or the severity of relapses were not available.

Published studies evaluating disease-modifying drug (DMD) exposure before, during, and after pregnancy in women with MS are also scarce. Of the 6 studies identified, 3 evaluated exposure to self-injectables during pregnancy, ${ }^{12-14}$ and 3 evaluated exposure to self-injectables or infusion therapies at conception or during pregnancy. ${ }^{8,15,16}$ The studies were conducted in Europe, ${ }^{13-15}$ Canada, ${ }^{12,16}$ and Argentina. ${ }^{8}$ US studies evaluating DMD utilization patterns in women with MS and pregnancy are uncommon. Studies evaluating the utilization of oral DMDs in women with MS and pregnancy, and studies evaluating DMD utilization during the pre- and postpregnancy periods, are also rare.

The objectives of this study were to use US administrative claims data to evaluate the rates of relapse and DMD treatment in women with MS and a live birth during prepregnancy, pregnancy, and postpartum.

\section{Methods}

\section{Data description}

This was a retrospective administrative claims database study using the IQVIA Real-World Data Adjudicated Claims-US database between January 1, 2006, and June 30, 2015. The IQVIA Real-World Data Adjudicated Claims-US database comprises fully adjudicated health plan claims data and enrollment information for commercial individuals. Information is received from health plans and self-insured employer groups throughout the United States for more than 150 million unique enrollees since 2006. This anonymous, patient-centric database includes all medical and pharmacy claims data (costs and descriptive services). Claims represent payments to providers for services rendered to covered health plan individuals. The data also include patient-level enrollment, which is a record of demographic variables including eligibility status (year of birth, sex, US Census region, eligibility by month). The enrollee population in the database is generally representative of the younger than 65 years, commercially insured population in the United States regarding both age and sex. The average length of enrollment is $\geq 39$ months, and more than 30 million patients have $\geq 3$ years of continuous enrollment (medical and pharmacy coverage). Each contributing plan's data undergo rigorous data quality review by IQVIA before its addition to the IQVIA Real-World Data Adjudicated Claims-US database.

The IQVIA Real-World Data Adjudicated Claims-US database is deidentified and compliant with the Health Insurance Portability and Accountability Act of 1996. As such, no institutional review board approval was required.

\section{Study population}

Patients were required to have at least one encounter with a diagnosis of MS (ICD-9-CM code: $340 . x x$ ) between January 1,2006 , and June 30, 2015. The start of the first MS encounter was the index date. Included patients were required to be female, between the ages of 18 and 64 as of the index date, and have at least one encounter with a diagnosis of pregnancy (table e-1, links.lww.com/WNL/A710) or a pregnancyrelated procedure (table e-2) from the index date to June 30, 2014. Patients were also required to have a live birth procedure code to be included in the live birth sample (table e-3). Only the first live birth was included in the analysis. The date of the live birth procedure was used to estimate the date of conception and the pregnancy periods (assumed 90-day trimesters) per the methodology reported in a published study by Knox et al. ${ }^{17}$ (2014) that evaluated the use of oral antidiabetics and pregnancy. Continuous eligibility 1 year before conception and 1 year after the live birth were additional required inclusion criteria for this cohort (i.e., 2-year, 9-month total follow-up period for each patient). For the analysis of DMD initiation post live birth, patients were required to have no claim for a DMD during the third trimester.

\section{Study outcomes}

Baseline demographic and clinical characteristics were evaluated. Demographic characteristics evaluated included age, region, and payer type. Clinical characteristics evaluated included overall comorbidity as measured by the Charlson Comorbidity Index and the individual rates of the most common comorbidities in MS (i.e., alcohol abuse, anxiety, arthritis [rheumatoid arthritis or osteoarthritis], chronic lung disease, depression, diabetes [type I and type II], gastrointestinal disease, hyperlipidemia, hypertension, and thyroid disease). These comorbidities were selected as they are among the most common in patients with MS based on 
a review of the published literature. ${ }^{18}$ Pregnancy-related risk factors were not considered in this evaluation.

Relapse was assessed using validated definitions of relapse 19,20 $^{19}$ that have been used in 19 previously published retrospective claims database evaluations: MS-related hospitalization, MSrelated emergency room (ER) visit, or MS-related outpatient visit with any corticosteroid prescription (IV or oral) within 7 days of the visit. ${ }^{19-37}$ Relapse rates were evaluated during the year before pregnancy, the 3 individual trimesters of pregnancy, puerperium (6 weeks after pregnancy), and the year after pregnancy. To make the rates reported over the individual time periods more comparable, they were converted to monthly rates by dividing the rate by the duration of the time period. The proportions of women with a pharmacy or medical claim for a DMD (self-injectable, oral, infusion, or any) were evaluated during the year before pregnancy, the 3 individual trimesters of pregnancy, puerperium, and the year after pregnancy.

\section{Study analyses}

Sample selection and creation of analytic variables were performed using the Instant Health Data Platform (Boston Health Economics, Inc., Boston, MA). Statistical analyses were undertaken with $\mathrm{R}$ version 3.2.1 ( $\mathrm{R}$ Foundation for Statistical Computing, Vienna, Austria) and SAS version 9.4 (SAS Institute Inc., Cary, NC). For descriptive (i.e., unadjusted) analyses, categorical variables were summarized using frequencies and percentages, and continuous variables were summarized using means (with confidence intervals [CIs]), SDs, and medians.

Differences in proportions were tested using a SAS generalized estimating equation approach, ${ }^{38}$ which uses an extension of a generalized linear model appropriate for longitudinal data. ${ }^{39}$ The generalized estimating equation model estimated population-average/marginal values, adjusting for a population with the characteristics included in the model, and used presence of relapse (yes/no) or presence of a DMD claim (yes/no) as the dependent measures in independent models. The model incorporated adjustment for the repeated measurements over time using four 90-day periods before pregnancy, the 3 trimesters of pregnancy, a 45-day puerperium period, and a 45-day initial postpartum period followed by three 90 -day postpartum periods. The events/trial method was used to adjust for the two 45-day time periods (relapse models only). Modeled variables included time (12 measurement periods), age, Charlson Comorbidity Index score, census region (missing values recoded as unknown), payer type (recoded as commercial vs other because of small cell sizes), and yes/no indicators for the following variables: anxiety, chronic lung disease, gastrointestinal disease, hyperlipidemia, hypertension, and thyroid disease. Alcohol abuse and arthritis were excluded because of small percentages reporting these conditions $(0.2 \%$ and $2.1 \%$, respectively, vs other comorbidities that ranged from $5.5 \%$ to $13.1 \%$ ) and because empirical analyses showed that inclusion of these variables resulted in poor model fit. Seven estimate statements were used to test for differences in the average baseline (i.e., prepregnancy) relapse rates/treatment proportions vs other time periods of interest. The 3 trimesters of pregnancy were also compared with puerperium. Tests for interactions between the time variable and the covariates were conducted.

\section{Data availability}

The data utilized for this study were obtained through a license agreement with IQVIA.

\section{Results}

\section{Baseline characteristics}

Of the 205,466 women with MS in the dataset, 10,630 had a pregnancy diagnosis claim, 5,022 had 1-year pre- and postpregnancy diagnosis eligibility, and 2,867 had a live birth. Of those, 2,158 had 1 year of continuous insurance eligibility pre- and postpregnancy. Patient baseline demographic and clinical characteristics are presented in table 1.

\section{Proportion of patients relapsing before, during, and after pregnancy}

The figure, A, shows the adjusted monthly rates of total relapses for patients with MS and a live birth overall and by type of relapse. Statistical model results confirmed that there were significant differences in overall relapse rates over time $(p<0.0001)$ and by age $(p=0.0004)$. No comorbidity indicators were statistically significant predictors of relapse. Regarding relapse time trends, compared with the prepregnancy period, the odds of relapse declined significantly during pregnancy (odds ratio [OR] 0.623, 95\% CI 0.521-0.744; $p<0.0001$ ), increased during puerperium (OR 1.710, 95\% CI 1.358-2.152; $p<0.0001$ ), and ended at a level during the last 3 postpartum quarters that was higher than the prepregnancy levels (OR 1.216, 95\% CI 1.052-1.406; $p=$ $0.0081)$. The OR between the pregnancy periods and puerperium was 2.745 (95\% CI 2.130-3.537; $p<0.0001$ ).

The figure, B, shows the adjusted monthly rates of relapses for patients with MS and a live birth by type of relapse. The majority of relapses were treated in an outpatient setting, and the odds of outpatient relapse declined significantly during pregnancy (OR 0.358, 95\% CI 0.268-0.478; $p<0.0001$ ), increased during puerperium (OR 1.607, 95\% CI $1.199-2.155 ; p=0.0015)$, and ended at a level during the last 3 postpartum quarters that was higher than the prepregnancy levels (OR 1.403, 95\% CI 1.179-1.670; $p<0.0001$ ). The OR between the pregnancy periods and puerperium for outpatient relapses was 4.488 (95\% CI 3.134-6.426; $p<0.0001$ ). Rates of relapses requiring ER visits remained relatively stable throughout the study period $(p>0.05)$. The odds of relapse requiring hospitalization increased significantly during the third trimester (OR 1.849, 95\% CI 1.280-2.670; $p=0.0011$ ) and during the puerperium period (OR 2.315, 95\% CI $1.478-3.626 ; p=0.0002$ ) compared with the prepregnancy period. The OR between the pregnancy periods and 
Table 1 Baseline demographic and clinical characteristics of women with multiple sclerosis and a live birth

\begin{tabular}{|c|c|}
\hline Characteristic & Value \\
\hline No. of patients & 2,158 \\
\hline \multicolumn{2}{|l|}{ Age, y } \\
\hline Mean (SD) & $30.3(4.7)$ \\
\hline Median & 30 \\
\hline \multicolumn{2}{|l|}{ Age grouping, y, n (\%) } \\
\hline $18-24$ & $229(10.6)$ \\
\hline $25-29$ & $727(33.7)$ \\
\hline $30-34$ & $810(37.5)$ \\
\hline $35-39$ & $336(15.6)$ \\
\hline $40-44$ & $55(2.5)$ \\
\hline$\geq 45$ & $1(0.05)$ \\
\hline \multicolumn{2}{|l|}{ Insurance, $\mathrm{n}(\%)^{\mathrm{a}}$} \\
\hline Commercial & $2,127(98.6)$ \\
\hline Medicaid & $27(1.3)$ \\
\hline Medicare & $4(0.2)$ \\
\hline \multicolumn{2}{|l|}{ Geographic region, $n(\%)^{b}$} \\
\hline Midwest & $676(32.2)$ \\
\hline Northeast & $610(29.0)$ \\
\hline South & $642(30.6)$ \\
\hline West & $172(8.2)$ \\
\hline \multicolumn{2}{|l|}{$\begin{array}{l}\text { Charlson Comorbidity Index } \\
\text { score }\end{array}$} \\
\hline Mean (SD) & $0.21(0.60)$ \\
\hline Median & 0 \\
\hline \multicolumn{2}{|l|}{ Comorbidity, n (\%) } \\
\hline Gastrointestinal disease & $283(13.1)$ \\
\hline Anxiety & $265(12.3)$ \\
\hline Thyroid disease & $234(10.8)$ \\
\hline Depression & $217(10.1)$ \\
\hline Hyperlipidemia & $169(7.8)$ \\
\hline Hypertension & $122(5.7)$ \\
\hline Chronic lung disease & $120(5.6)$ \\
\hline Diabetes & $57(2.6)$ \\
\hline Arthritis & $46(2.1)$ \\
\hline Alcohol abuse & $5(0.2)$ \\
\hline
\end{tabular}

a Percentages do not equal $100.0 \%$ because of rounding.

${ }^{b}$ Individual numbers may not add up to the total number of patients included in the final analysis because of missing values.

cPrepregnancy diagnosis. puerperium for relapses requiring hospitalization was 2.050 (95\% CI 1.284-3.272; $p=0.0026)$.

Tests for interactions between the time variable and the covariates were conducted. The solution would not converge with all of the interactions in the model. Taking out the Charlson score or the specific comorbidities resulted in model convergence. None of the specific comorbidities were significant. There was a significant interaction between time and the Charlson comorbidity score without the specific comorbidities included in the model; there was a slightly greater relapse rate at all time periods among patients with relapse, with the most notable effect postpregnancy relative to those without comorbidity. Age, census region, and presence of commercial insurance did not interact with time.

\section{Proportion of patients with DMD treatment before, during, and after pregnancy}

Statistical model results also showed that there were significant differences in the proportion of patients with DMD treatment over time $(p<0.0001)$. The 2 comorbidity indicators that were significant predictors of DMD treatment were the presence of gastrointestinal disease $(p=0.0010)$ and hyperlipidemia $(p=$ 0.0473 ). The proportion of women with DMD treatment was rather low overall, peaking at $25.5 \% 9$ to 12 months postpartum (table 2). Compared with the prepregnancy period, the proportion of women with DMD treatment declined significantly during pregnancy (OR 0.171, 95\% CI 0.144-0.203; $p<$ 0.0001 ), remained lower during puerperium (OR 0.361, 95\% CI $0.312-0.418 ; p<0.0001$ ), and ended at a level during the last 3 postpartum quarters that was higher than the prepregnancy levels (OR 1.259, 95\% CI 1.156-1.371; $p<0.0001$ ). The highest $\mathrm{OR}$ was between pregnancy and the puerperium period (OR 2.106, 95\% CI 1.740-2.548; $p<0.0001$ ). Most patients were treated with self-injectable DMDs. The use of oral and infusion DMDs in this sample was very low $(<3.1 \%)$.

The proportion of patients with DMD treatment was also described by the number of relapses women experienced prior to pregnancy. As expected, the proportion with DMD treatment was higher in women with a greater number of relapses during the year before pregnancy. The proportion of women with DMD treatment across all patient subgroups was low during the second and third trimesters (range: 0.00\%-7.42\%). In comparison, among women with 3 or more relapses during the year before pregnancy, up to two-thirds had DMD treatment before pregnancy and during the year after delivery.

\section{DMD treatment initiation after pregnancy}

Of 2,158 women with MS, a live birth, and 1-year eligibility preand postpregnancy, 64 had a DMD prescription during the third trimester and were removed from the analysis of DMD treatment initiation postpregnancy. The demographics of the 2,094 remaining patients were very similar to the original sample (data not shown). The proportion of women with a live birth initiating a DMD within 1 year was $28.5 \%(n=596)$. For 
Figure Adjusted monthly rates of total multiple sclerosis relapses before, during, and after pregnancy (A) overall and (B) by type of relapse
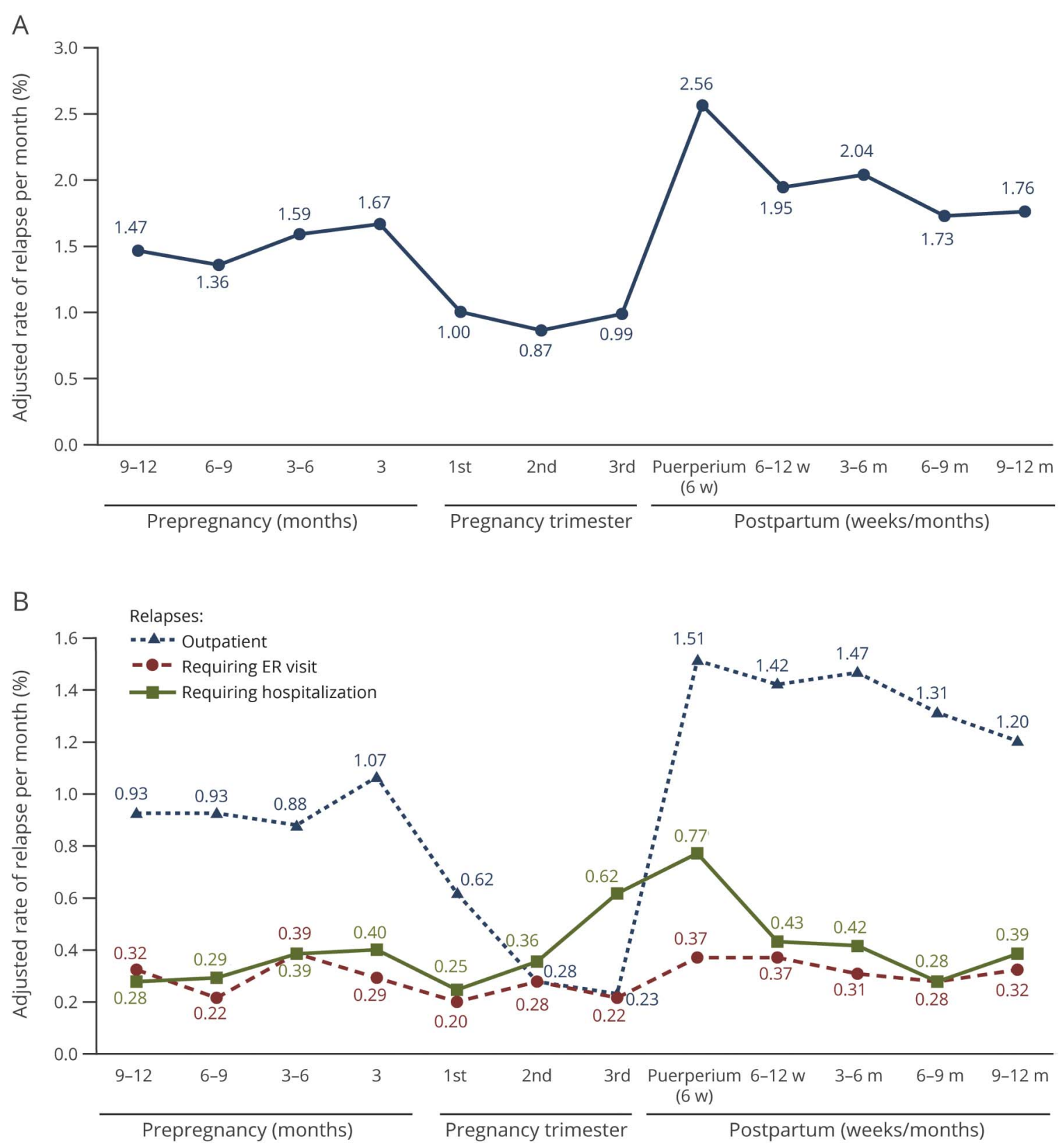

$\mathrm{ER}=$ emergency room.

women initiating a DMD within 1 year, mean $(\mathrm{SD})$ time from live birth to first DMD treatment was 119.0 (92.94) days; median time to first DMD was 93.5 days. Approximately half of patients receiving a DMD within 1 year initiated it within 90 days $(47.8 \%)$, and three-quarters initiated a DMD within 6 months $(75.5 \%)$. The proportion of patients initiating DMDs within 1 year after live birth increased with higher numbers of relapses during the prepregnancy period (table 3 ).

Patients treated with DMDs 1 year prepregnancy were more likely to initiate DMD treatment within 1 year following the live birth (72.6\% vs $12.4 \%$ without DMD exposure 1 year prepregnancy). However, patients tended to wait more than 100 days after birth to initiate DMD treatment regardless of past use. The mean time to initiation was 147.9 (SD, 103.59) days for those without DMD exposure prepregnancy vs 105.3 (SD, 84.21) days for those with DMD exposure prepregnancy; median 122 and 84 days, respectively.

\section{Discussion}

Pregnancy in women with MS can be complex both from a patient and a provider perspective. ${ }^{40}$ The majority of 
Table 2 The proportion of women with self-injectable, oral, or infusion DMD treatment before, during, and after pregnancy in women with multiple sclerosis and a live birth

\begin{tabular}{|c|c|c|c|c|}
\hline Time period, n (\%) & Any DMD & Self-injectable DMD & Oral DMD & Infusion DMD \\
\hline 9-12 mo prepregnancy & $442(20.5)$ & $400(18.5)$ & $5(0.2)$ & $2(0.1)$ \\
\hline 6-9 mo prepregnancy & $463(21.5)$ & $416(19.3)$ & $6(0.3)$ & $1(0.05)$ \\
\hline 3-6 mo prepregnancy & $445(20.6)$ & $398(18.4)$ & $7(0.3)$ & $0(0.0)$ \\
\hline 3 mo prepregnancy & $383(17.7)$ & $343(15.9)$ & $4(0.2)$ & $1(0.05)$ \\
\hline First trimester & $260(12.0)$ & $231(10.7)$ & $4(0.2)$ & $2(0.1)$ \\
\hline Second trimester & $41(1.9)$ & $37(1.7)$ & $2(0.1)$ & $1(0.05)$ \\
\hline Third trimester & $64(3.0)$ & $62(2.9)$ & $2(0.1)$ & $0(0.0)$ \\
\hline Puerperium ( 6 wk postpartum) & $180(8.3)$ & $164(7.6)$ & $3(0.1)$ & $0(0.0)$ \\
\hline 7-12 wk postpartum & $279(12.9)$ & 235 (10.9) & $14(0.6)$ & $3(0.1)$ \\
\hline 3-6 mo postpartum & $474(22.0)$ & $392(18.2)$ & $34(1.6)$ & $4(0.2)$ \\
\hline 6-9 mo postpartum & $528(24.5)$ & $418(19.4)$ & $52(2.4)$ & $4(0.2)$ \\
\hline 9-12 mo postpartum & $550(25.5)$ & $422(19.6)$ & $66(3.1)$ & $5(0.2)$ \\
\hline
\end{tabular}

Abbreviation: $\mathrm{DMD}=$ disease-modifying drug.

Table 3 DMD initiation during the year after pregnancy in women with multiple sclerosis with a live birth and no DMD treatment in the third trimester by number of prepregnancy relapses

\begin{tabular}{|c|c|c|c|c|}
\hline & \multicolumn{4}{|c|}{ No. of relapses prepregnancy } \\
\hline & $0(n=1,798)$ & $1(n=212)$ & $2(n=61)$ & $\geq 3(n=23)$ \\
\hline DMD initiation, $\mathbf{n}(\%)$ & $441(24.5)$ & $108(50.9)$ & $33(54.1)$ & $14(60.9)$ \\
\hline Mean (SD) time to initiation, $d$ & $123.6(96.0)$ & $108.0(84.4)$ & $120.8(83.6)$ & $55.6(37.9)$ \\
\hline Median time to initiation, $d$ & 99 & 80 & 98 & 49.5 \\
\hline \multicolumn{5}{|l|}{ Time to DMD initiation, $d, n(\%)$} \\
\hline $0-29$ & $69(15.6)$ & $19(17.6)$ & $0(0.0)$ & $5(35.7)$ \\
\hline $30-59$ & $83(18.8)$ & $18(16.7)$ & $1(3.0)$ & $3(21.4)$ \\
\hline $60-89$ & $51(11.6)$ & $21(19.4)$ & $3(9.1)$ & $3(21.4)$ \\
\hline $90-119$ & $51(11.6)$ & $9(8.3)$ & $7(21.2)$ & $2(14.3)$ \\
\hline $120-149$ & $40(9.1)$ & 15 (13.9) & $3(9.1)$ & $1(7.1)$ \\
\hline $150-179$ & $29(6.6)$ & $7(6.5)$ & $2(6.1)$ & $0(0.0)$ \\
\hline $180-209$ & $29(6.6)$ & $5(4.6)$ & $2(6.1)$ & $0(0.0)$ \\
\hline 210-239 & $25(5.7)$ & $5(4.6)$ & $4(12.1)$ & $0(0.0)$ \\
\hline $240-269$ & $14(3.2)$ & $2(1.9)$ & $2(6.1)$ & $0(0.0)$ \\
\hline 270-299 & $18(4.1)$ & $2(1.9)$ & $1(3.0)$ & $0(0.0)$ \\
\hline $300-329$ & $16(3.6)$ & $3(2.8)$ & $1(3.0)$ & $0(0.0)$ \\
\hline $330-365$ & $16(3.6)$ & $2(1.9)$ & $7(21.2)$ & $0(0.0)$ \\
\hline
\end{tabular}

Abbreviation: $\mathrm{DMD}=$ disease-modifying drug. 
patients with MS are women, and clinical onset of MS most often occurs during childbearing age, in the third and fourth decades of life. ${ }^{41}$ It is estimated that between one-fifth and one-third of women with MS deliver a child after disease onset, ${ }^{42,43}$ making pregnancy in women with MS of significant relevance to patients, their family members, and their health care providers. ${ }^{44}$ More evidence to support decision-making in women with MS of childbearing age is needed in order to improve available clinical support, health care services, and quality of life for this population..$^{40,45}$

The availability of health services utilization data, commonly referred to as administrative claims data, affords a unique opportunity to assess and monitor disease and treatment patterns in patients with MS across large, clinically representative "real-world" populations. ${ }^{46}$ These rich data sources, derived from reimbursement information or the payment of bills for health care services and commodities, ${ }^{9}$ can improve our knowledge of the interactions that pregnant women with MS have with the health care system, and of the reciprocal influences between pregnancy and MS.

Our findings are consistent with previous studies outside of North America evaluating relapse rates in women with MS during pregnancy. ${ }^{1-11}$ The overall rate of relapse decreased during pregnancy, increased during puerperium, and then decreased after puerperium to similar rates observed in the prepregnancy period. ${ }^{2-11}$ When relapses were stratified into levels of resource utilization intensity, which served as proxies for relapse severities, it was observed that the majority of relapses were treated in an outpatient setting, and that the rate of outpatient relapses very sharply declined during pregnancy. Rates of relapses requiring ER visits remained relatively stable throughout the study period, while rates of relapses requiring hospitalization increased in the third trimester and during puerperium. The increase during the third trimester may reflect increased monitoring of these patients through this critical late pregnancy period. In contrast, since these relapses are estimated based on patient utilization of health care services, the outpatient relapses may be underestimated if patients did not obtain corticosteroids because of concerns regarding taking medications during pregnancy. Therefore, our data may be reflective of moderate to severe relapses, but not mild relapses.

The current study differs from and complements the previous studies evaluating the utilization of DMDs in pregnancy because it is a US, observational ("real-world"), claims-based study that assessed the patterns of utilization of DMDs before, during, and after pregnancy., ${ }^{8,12-16}$ The proportion of women with DMD treatment was rather low throughout all time periods, beginning with approximately $20 \%$ of patients having a claim for DMD treatment at 9 to 12 months prepregnancy, expectantly declining to $<2 \%$ during the second trimester, and peaking at approximately $25 \% 9$ to 12 months postpartum. Very few patients in this study population used oral and infusion DMDs $(<3.1 \%)$, possibly because of their later availability (fingolimod was the first oral DMD and was approved in 2010). The preferred use of injectable therapies may reflect physician and patient preference to utilize DMDs with longer safety data in this vulnerable population, in case of early pregnancy exposure. The use of DMDs in pregnancy remains controversial and the current recommendations are to avoid DMDs in pregnancy unless the risks of disease worsening significantly outweigh the risks of DMD exposure to the fetus. ${ }^{45}$ Consistent with this, DMD treatment was more common in women with a greater number of relapses during the year before pregnancy. Up to two-thirds of women with 3 or more relapses during the year before pregnancy had DMD treatment before pregnancy and during the year after delivery, but only a small proportion $(<7.5 \%)$ received DMDs during pregnancy. The proportion of women who did not receive a DMD in the third trimester but initiated a DMD within 1 year after delivery was 28.5\%; approximately half of these patients initiated the DMD within 90 days, and three-quarters initiated the DMD within 6 months.

Given the low proportion of patients treated with DMDs in the sample (aside from women with 3 or more relapses in the year before pregnancy), the study may be indicative of a natural history study. It was surprising that nearly 20 years after the Pregnancy in Multiple Sclerosis study, a minority of eligible patients with MS are receiving DMDs prior to pregnancy. The intent of the study was to provide women with MS who are considering pregnancy or those who are pregnant and their health care professionals with information on other patients' experiences of care, the burden of disease, and realworld treatment approaches. The size and relative ease of analysis with this retrospective administrative database, despite its limitations, affords us a great tool for understanding "real-world" outcomes and opportunities for improving patient care. The study should be repeated to account for any differences that may be observed in these trends over the last 3 to 5 years, with the higher utilization of oral and infusion therapies.

Claims data are not specifically collected for research purposes, and there can be missing information that limits the inferences that can be made from the data. For example, the data do not include Expanded Disability Status Scale score, ${ }^{47}$ disease duration, or the numbers or outcomes of prior pregnancies for this population. Having these data would have provided additional insights into timing and choices of postpartum treatment decisions. The ICD-9-CM code used to identify patients in this sample does not differentiate among patients with primary progressive, relapsing-remitting, or secondary progressive MS. ${ }^{48}$ Patients could have had ER visits and hospitalizations for reasons other than their MS, but this could not be discerned from the data. It is possible that corticosteroids were used for treatment of other indications, including allergic rhinitis, asthma, dermatitis, ulcerative colitis, leukemia and lymphoma, gout, and rheumatoid arthritis. However, the corticosteroid claim had to follow an MSrelated outpatient visit within 7 days. This definition of 
outpatient relapse has been used in 19 previously published, retrospective claims database analyses and has been validated in 2 studies. ${ }^{19-37}$ The date of the live birth procedure was used to estimate the date of conception and the pregnancy periods (per Knox et al. ${ }^{17}$ ), possibly resulting in misclassification of the prepregnancy period and the following trimesters in some cases. Because of the size of the observed effect, this possible misclassification in some cases is not likely to alter the results fundamentally. Lactation status also could not be assessed in this sample. The 90-day delay in DMD initiation may be related to maternal breastfeeding for 3 months postpartum as the duration of breastfeeding in the United States is typically shorter than in other countries. ${ }^{49}$ Also, retrospective administrative claims data may have not included some events if not reimbursed by the health plan (e.g., if out of network). Furthermore, this dataset likely underrepresents patients in the western region of the United States, indigent/minority populations on federal or state health insurance coverages, and, possibly, more disabled populations. Finally, DMD treatment was assessed using claims data, and while patients may have had drug on hand, they may not have been taking it during the study periods that were reported.

This study effectively used US administrative claims data to characterize the patient experience of care in women with MS and a live birth. Patients' interactions with the health care system and the interactions between pregnancy and MS were evaluated across a large, real-world population. Despite their noted limitations, claims data are a valuable resource for exploratory analyses of a variety of health services research questions. Further prospective, real-world studies are needed to explore practice patterns and neurologic, obstetric, and pediatric outcomes in this patient population.

\section{Author contributions}

All authors contributed to the study concept and design; acquisition, analysis, or interpretation of data; drafting the manuscript or revising it critically; and the approval of the version for submission.

\section{Acknowledgment}

The authors thank Dr. Chris Kozma (CK Consulting Associates, LLC, Saint Helena Island, SC) for assistance with statistical analyses, and Michele Springer (Caudex, New York, $\mathrm{NY}$ ) for assistance with editing and revising the manuscript for nonintellectual content.

\section{Study funding}

Study funded by EMD Serono, Inc., Rockland, MA (a business of Merck KGaA, Darmstadt, Germany). The authors received no funding for their authorship responsibilities in the development of this manuscript.

\section{Disclosure}

M. Houtchens: funding support from EMD Serono, Inc. (a business of Merck KGaA, Darmstadt, Germany); support for service on scientific advisory boards from Biogen, Sanofi
Genzyme, Teva Neuroscience, and Novartis; and research support from Sanofi Genzyme and Biogen. N. Edwards: employee of Health Services Consulting Corporation. Health Services Consulting Corporation received funding from EMD Serono, Inc. (a business of Merck KGaA, Darmstadt, Germany) to run the analysis. A. Phillips: employee of EMD Serono, Inc., Rockland, MA (a business of Merck KGaA, Darmstadt, Germany).

\section{Publication history}

Received by Neurology December 15, 2017. Accepted in final form July 16, 2018.

\section{References}

1. Confavreux C, Hutchinson M, Hours MM, Cortinovis-Tourniaire P, Moreau T. Rate of pregnancy-related relapse in multiple sclerosis.Pregnancy in Multiple Sclerosis Group. N Engl J Med 1998;339:285-291.

2. Cuello JP, Martinez Gines ML, Martin Barriga ML, de Andrés C. Multiple sclerosis and pregnancy: a single-centre prospective comparative study. Neurologia 2017;32: 92-98.

3. D'hooghe MB, Nagels G, Bissay V, De Keyser J. Modifiable factors influencing relapses and disability in multiple sclerosis. Mult Scler 2010;16:773-785.

4. Hughes SE, Spelman T, Gray OM, et al. Predictors and dynamics of postpartum relapses in women with multiple sclerosis. Mult Scler 2014;20:739-746.

5. Salemi G, Callari G, Gammino M, et al. The relapse rate of multiple sclerosis changes during pregnancy: a cohort study. Acta Neurol Scand 2004;110:23-26.

6. Vukusic S, Hutchinson M, Hours M, et al. Pregnancy and multiple sclerosis (the PRIMS study): clinical predictors of post-partum relapse. Brain 2004;127: 1353-1360.

7. Fares J, Nassar AH, Gebeily S, Kobeissy F, Fares Y. Pregnancy outcomes in Lebanese women with multiple sclerosis (the LeMS study): a prospective multicentre study. BMJ Open 2016;6:e011210.

8. Fernandez Liguori N, Klajn D, Acion L, et al. Epidemiological characteristics of pregnancy, delivery, and birth outcome in women with multiple sclerosis in Argentina (EMEMAR study). Mult Scler 2009; 15:555-562.

9. Finkelsztejn A, Fragoso YD, Ferreira ML, et al. The Brazilian database on pregnancy in multiple sclerosis. Clin Neurol Neurosurg 2011;113:277-280.

10. Hellwig K, Brune N, Haghikia A, et al. Reproductive counselling, treatment and course of pregnancy in 73 German MS patients. Acta Neurol Scand 2008;118:24-28.

11. Popova EV, Kukel' TM, Muravin AI, Bolko AN, Murashko AV, Gusev EI. Pregnancy and delivery in women with multiple sclerosis: a retrospective analysis [in Russian]. Zh Nevrol Psikhiatr Im S S Korsakova 2013;113:52-56.

12. Boskovic R, Wide R, Wolpin J, Bauer DJ, Koren G. The reproductive effects of beta interferon therapy in pregnancy: a longitudinal cohort. Neurology 2005;65:807-811.

13. Hellwig K, Haghikia A, Rockhoff M, Gold R. Multiple sclerosis and pregnancy: experience from a nationwide database in Germany. Ther Adv Neurol Disord 2012;5: 247-253.

14. Weber-Schoendorfer C, Schaefer C. Multiple sclerosis, immunomodulators, and pregnancy outcome: a prospective observational study. Mult Scler 2009;15:1037-1042.

15. De Las Heras V, de Andres C, Tellez N, Tintore M. Pregnancy in multiple sclerosis patients treated with immunomodulators prior to or during part of the pregnancy: a descriptive study in the Spanish population. Mult Scler 2007;13:981-984.

16. Lu E, Dahlgren L, Sadovnick A, Sayao A, Synnes A, Tremlett H. Perinatal outcomes in women with multiple sclerosis exposed to disease-modifying drugs. Mult Scler 2012; 18:460-467.

17. Knox CA, Delaney JA, Winterstein AG. Anti-diabetic drug utilization of pregnant diabetic women in US managed care. BMC Pregnancy Childbirth 2014;14:28.

18. Marrie RA, Cohen J, Stuve O, et al. A systematic review of the incidence and prevalence of comorbidity in multiple sclerosis: overview. Mult Scler 2015;21:263-281.

19. Capkun G, Lahoz R, Verdun E, et al. Expanding the use of administrative claims databases in conducting clinical real-world evidence studies in multiple sclerosis. Curr Med Res Opin 2015;31:1029-1039.

20. Chastek BJ, Oleen-Burkey M, Lopez-Bresnahan MV. Medical chart validation of an algorithm for identifying multiple sclerosis relapse in healthcare claims. J Med Econ 2010;13:618-625.

21. Boster A, Nicholas J, Wu N, et al. Comparative effectiveness research of diseasemodifying therapies for the management of multiple sclerosis: analysis of a large health insurance claims database. Neurol Ther 2017;6:91-102.

22. Burks J, Marshall TS, Ye X. Adherence to disease-modifying therapies and its impact on relapse, health resource utilization, and costs among patients with multiple sclerosis. Clinicoecon Outcomes Res 2017;9:251-260.

23. Johnson BH, Bonafede MM, Watson C. Platform therapy compared with natalizumab for multiple sclerosis: relapse rates and time to relapse among propensity scorematched US patients. CNS Drugs 2015;29:503-510.

24. Bergvall N, Lahoz R, Reynolds T, Korn JR. Healthcare resource use and relapses with fingolimod versus natalizumab for treating multiple sclerosis: a retrospective US claims database analysis. Curr Med Res Opin 2014;30:1461-1471. 
25. Bergvall N, Makin C, Lahoz R, et al. Relapse rates in patients with multiple sclerosis switching from interferon to fingolimod or glatiramer acetate: a US claims database study. PLoS One 2014;9:e88472.

26. Bergvall N, Makin C, Lahoz R, et al. Comparative effectiveness of fingolimod versus interferons or glatiramer acetate for relapse rates in multiple sclerosis: a retrospective US claims database analysis. Curr Med Res Opin 2013;29:1647-1656.

27. Tan H, Cai Q, Agarwal S, Stephenson JJ, Kamat S. Impact of adherence to diseasemodifying therapies on clinical and economic outcomes among patients with multiple sclerosis. Adv Ther 2011;28:51-61.

28. Castelli-Haley J, Oleen-Burkey MA, Lage MJ, Johnson K. Glatiramer acetate and interferon beta-1a for intramuscular administration: a study of outcomes among multiple sclerosis intent-to-treat and persistent-use cohorts. J Med Econ 2010;13: 464-471.

29. McQueen RB, Livingston T, Vollmer T, et al. Increased relapse activity for multiple sclerosis natalizumab users who become nonpersistent: a retrospective study. J Manag Care Spec Pharm 2015;21:210-218.

30. Lage MJ, Carroll CA, Fairman KA. Using observational analysis of multiple sclerosis relapse to design outcomes-based contracts for disease-modifying drugs: a feasibility assessment. J Med Econ 2013;16:1146-1153.

31. Parise H, Laliberte F, Lefebvre P, et al. Direct and indirect cost burden associated with multiple sclerosis relapses: excess costs of persons with MS and their spouse caregivers. J Neurol Sci 2013;330:71-77.

32. Raimundo $\mathrm{K}$, Tian $\mathrm{H}$, Zhou $\mathrm{H}$, et al. Resource utilization, costs and treatment patterns of switching and discontinuing treatment of MS patients with high relapse activity. BMC Health Serv Res 2013;13:131.

33. Steinberg SC, Faris RJ, Chang CF, Chan A, Tankersley MA. Impact of adherence to interferons in the treatment of multiple sclerosis: a non-experimental, retrospective, cohort study. Clin Drug Investig 2010;30:89-100.

34. Ollendorf DA, Castelli-Haley J, Oleen-Burkey M. Impact of co-prescribed glatiramer acetate and antihistamine therapy on the likelihood of relapse among patients with multiple sclerosis. J Neurosci Nurs 2008;40:281-290.

35. Ollendorf DA, Jilinskaia E, Oleen-Burkey M. Clinical and economic impact of glatiramer acetate versus beta interferon therapy among patients with multiple sclerosis in a managed care population. J Manag Care Pharm 2002;8:469-476.
36. Castelli-Haley J, Oleen-Burkey MA, Lage MJ, Johnson KP. Glatiramer acetate and interferon beta- $1 \mathrm{~b}$ : a study of outcomes among patients with multiple sclerosis. Adv Ther 2009;26:552-562

37. Castelli-Haley J, Oleen-Burkey M, Lage MJ, Johnson KP. Glatiramer acetate versus interferon beta-1a for subcutaneous administration: comparison of outcomes among multiple sclerosis patients. Adv Ther 2008;25:658-673.

38. Liang KY, Zeger SL. Longitudinal data analysis using generalized linear models. Biometrika 1986;73:13-22.

39. Stokes ME, David CS, Koch GG. Categorical Data Analysis Using SAS, 3rd ed. Cary, NC: SAS Institute Inc.; 2012.

40. Wundes A, Pebdani RN, Amtmann D. What do healthcare providers advise women with multiple sclerosis regarding pregnancy? Mult Scler Int 2014;2014:819216.

41. National Multiple Sclerosis Society. Pregnancy and Reproductive Issues. National MS Society [serial online]. 2017. Available at: nationalmssociety.org/Living-Well-WithMS/Diet-Exercise-Healthy-Behaviors/Womens-Health/Pregnancy. Accessed December 7, 2017.

42. Runmarker B, Andersen O. Pregnancy is associated with a lower risk of onset and a better prognosis in multiple sclerosis. Brain 1995;118(pt 1):253-261.

43. Weinshenker BG, Hader W, Carriere W, Baskerville J, Ebers GC. The influence of pregnancy on disability from multiple sclerosis: a population-based study in Middlesex County, Ontario. Neurology 1989;39:1438-1440.

44. van der Kop ML, Pearce MS, Dahlgren L, et al. Neonatal and delivery outcomes in women with multiple sclerosis. Ann Neurol 2011;70:41-50.

45. Bove R, Alwan S, Friedman JM, et al. Management of multiple sclerosis during pregnancy and the reproductive years: a systematic review. Obstet Gynecol 2014;124: $1157-1168$.

46. Cadarette SM, Wong L. An introduction to health care administrative data. Can J Hosp Pharm 2015;68:232-237.

47. Kurtzke JF. Rating neurologic impairment in multiple sclerosis: an Expanded Disability Status Scale (EDSS). Neurology 1983;33:1444-1452.

48. Van der Kop ML, Pearce MS, Dahlgren L, et al. Neonatal and delivery outcomes in women with multiple sclerosis. Ann Neurol 2011;70:41-50.

49. Wolf JH. Low breastfeeding rates and public health in the United States. Am J Public Health 2003;93:2000-2010. 


\section{Neurology}

\section{Relapses and disease-modifying drug treatment in pregnancy and live birth in US women with MS \\ Maria K. Houtchens, Natalie C. Edwards and Amy L. Phillips}

Neurology 2018;91;e1570-e1578 Published Online before print September 28, 2018

DOI 10.1212/WNL.0000000000006382

This information is current as of September 28, 2018

\section{Updated Information \&} Services

References

Citations

Subspecialty Collections

Permissions \& Licensing

Reprints including high resolution figures, can be found at: http://n.neurology.org/content/91/17/e1570.full

This article cites 47 articles, 4 of which you can access for free at: http://n.neurology.org/content/91/17/e1570.full\#ref-list-1

This article has been cited by 1 HighWire-hosted articles: http://n.neurology.org/content/91/17/e1570.full\#\#otherarticles

This article, along with others on similar topics, appears in the following collection(s):

Multiple sclerosis

http://n.neurology.org/cgi/collection/multiple_sclerosis

Information about reproducing this article in parts (figures,tables) or in its entirety can be found online at:

http://www.neurology.org/about/about_the_journal\#permissions

Information about ordering reprints can be found online:

http://n.neurology.org/subscribers/advertise

Neurology ${ }^{\circledR}$ is the official journal of the American Academy of Neurology. Published continuously since 1951 , it is now a weekly with 48 issues per year. Copyright Copyright (C) 2018 The Author(s). Published by Wolters Kluwer Health, Inc. on behalf of the American Academy of Neurology.. All rights reserved. Print ISSN: 0028-3878. Online ISSN: 1526-632X.

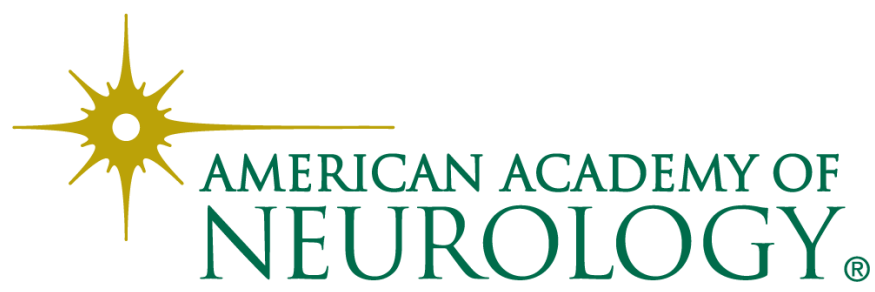

